\title{
Investigations on real time RSSI based outdoor target tracking using kalman filter in wireless sensor networks
}

\author{
K. Vadivukkarasi, R. Kumar \\ Department of Electronics and Communication Engineering, SRM Institute of Science and Technology, India
}

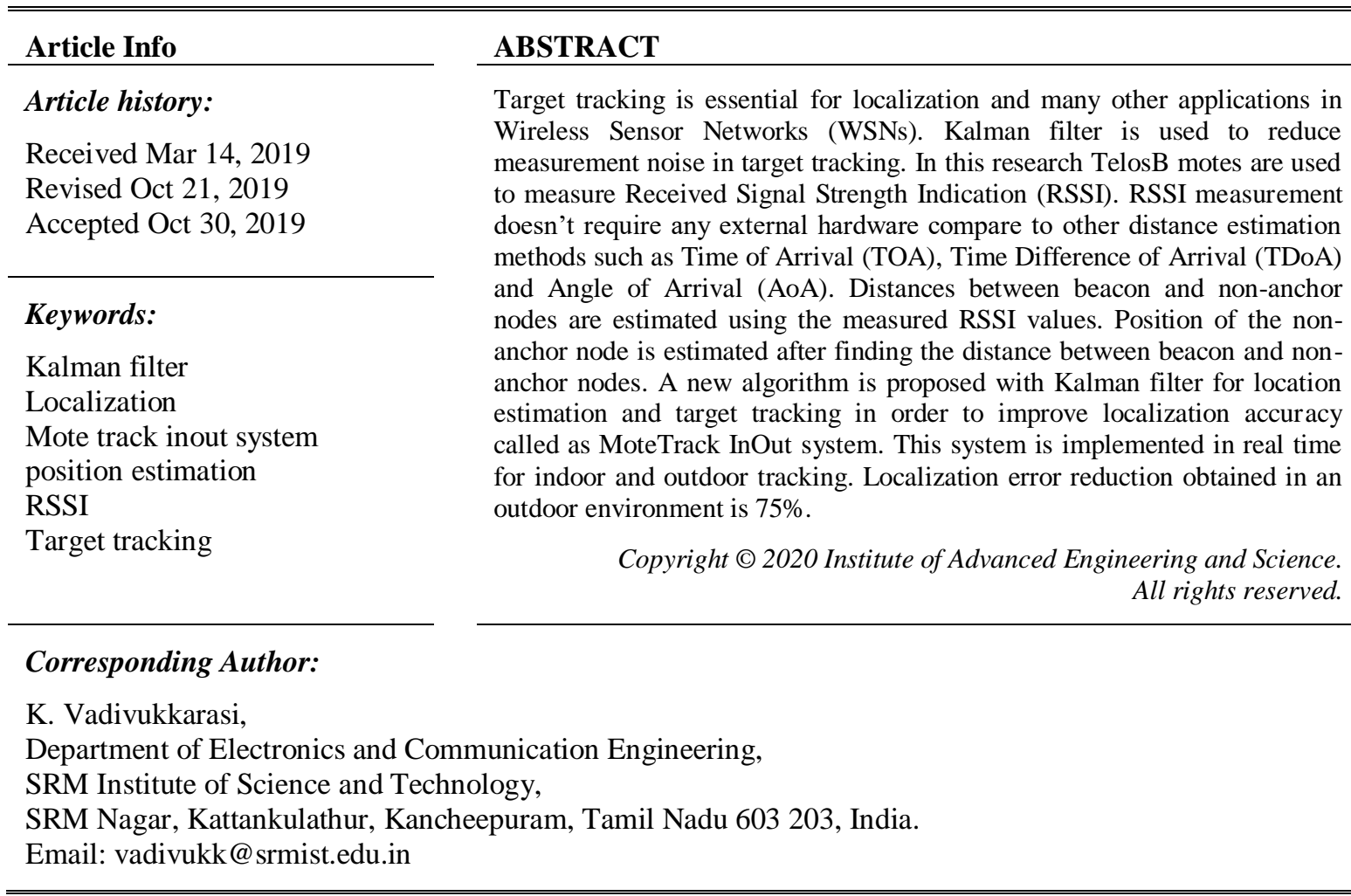

\section{INTRODUCTION}

A wireless sensor network is composed of a large number of inexpensive, low-power and tiny sensors, which are randomly and densely deployed in the surveillance area [1]. These tiny sensors, which consist of sensing, data processing, and communicating components, collaboratively monitor the event of interest, process the sensed data, and provide resultant information about the monitored events for a number of potential applications, ranging from battlefield monitoring and environmental surveillance to health care [2-5]. Object tracking and localization are the important problems of WSNs [6, 7]. Energy consumption and accuracy enhancement are the recent concerns in WSN. Localization algorithms are classified as range based and range free localization. Range free localization does not require distance estimation. There are four basic range based techniques in WSN, namely AOA, TOA, TDOA and RSSI. RSSI based localization is the cost-effective implementation because no extra hardware required for distance measurement compare to other ranging techniques. But the drawback of RSSI based localization is the relatively lower accuracy. Many localization algorithms have been introduced to improve the localization accuracy [8-10].

The rest of the paper is organized as follows: Section 2 gives the Literature review. Section 3 presents overview of MoteTrack InOut system and it explains the experimental setup used in this work. In Section 4 describes about distance and position estimation methods respectively. Section 5 introduces Kalman filter and section 6 focuses on MoteTrack InOut system algorithm. Section 7 the results from outdoor environment is provided. Conclusion is provided at the end of paper. 


\section{RELATED WORK}

In [11], an enhanced version of Disk Overlapping localization scheme is proposed by attaching mass coefficients to each point of the possible locations in the region. The position estimation is derived in [12], as weighted least square problem and the location estimates are computed in a decentralized manner. Location estimation may also be defined in a dynamic scenario with the help of location tracking of a single mobile node (MN). With the information provided by previous locations and the mobility of nodes enable us to gain better estimation accuracy and a smoother trajectory in this approach of location tracking. Kalman Filter (KF) has been widely utilized for modeling the tracking of mobile nodes in the literature.

A Unified Kalman Tracking (UKT) algorithm is introduced in [13]. As this algorithm combines the previously proposed two-step least square method into KF state formulation and provides a simultaneous solution to the location estimation and tracking problems. Considering RSS variations, [14] has the SNRs at sensor nodes by a 2nd order polynomial function for their specific experimental setup. Later, KF applied to the predicted SNRs to track position changes. In [15] the tracking task of a mobile node is also modeled by KF. Lateralization with nearest three estimated nodes gives advantage to estimate the coordinates of the object. This has been experimented for straight or circular movements of the mobile nodes. Another proposed method in [16] has improved the performance of KF by renovating the estimated velocity in state equations through a direction finding process. In this paper, an adaptive Mote Track InOut tracking technique is developed to track the variations of the location estimations obtained. The initially modeled KF has been modified to account for the convergence requirement, uncertainties about system dynamic model and noise description. The proposed adaptive Kalman tracking scheme can well adapt to the rapid changes of movement and environment [17-19].

\section{EXPERIMENTAL SET UP OF MOTE TRACK INOUT SYSTEM}

In an indoor environment, for a moving target the localization error using Log Normal Shadowing Model (LNSM), Kalman filter and proposed method is $2.231 \mathrm{~m}, 1.007 \mathrm{~m}$ and $0.818 \mathrm{~m}$ respectively. The localization error is reduced using proposed method but over lapping occurred in the tracking path. MoteTrack InOut is used and it is found that localization error is $0.570 \mathrm{~m}$ and there is no overlapping in tracking path. Localization error reduction obtained using the proposed method along with the Kalman filter for a moving target is $1.66 \mathrm{~m}$ when compared to LNSM [20]. The outdoor experiments are conducted in an open play ground. Ground is surrounded by number of trees and plants. Figure 1 show the experimental test bed set up of MoteTrack InOut system. It consists of four beacon nodes and one mobile node.

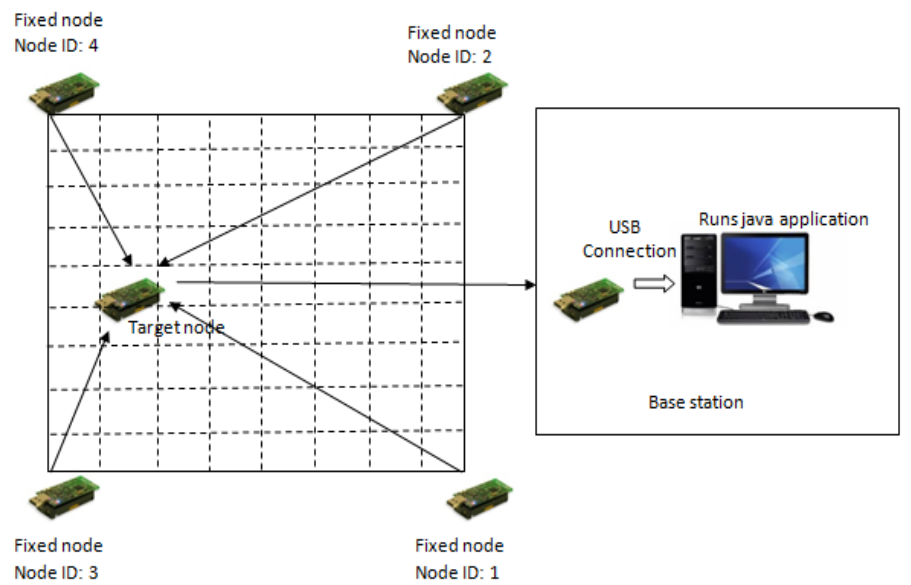

Figure 1. The experimental test bed

As a node TelosB mote is employed. It is a low power embedded device with chipcon CC2420 [21, 22]. It provides a digital received signal strength indicator (RSSI) that may be read any time. TelosB mote has a USB port, applying that it is connected to PC or laptop. Operating system for this mote is Tiny OS. We can develop a program in PC or laptop applying NesC language and upload a program into the TelosB mote as well as erase a program and load a new program. Beacon node will send a empty packet periodically to the mobile node. This periodic message consists of two information's such as source ID and 
power level. There are eight power levels used in TelosB mote. The highest and default power level is 31 and its equivalent value in $\mathrm{dBm}$ (decibel-mill watt) and mill watts is 0 and 1 respectively. The beacon nodes are fixed at the four places of the ground with coordinates $(0,1),(0,2.5),(1,7.1),(2.5,7.1)$. The moving target node is carried by a person. The walking target traverses the corridor at a varying velocity. The RSSI measurements from the anchor nodes are collected and forwarded to the sink node. The sink node is connected to PC where the localization algorithm is implemented.

\section{DISTANCE AND POSITION ESTIMATION}

Log normal shadowing model (LNSM) is used to estimate distance between beacon node and unknown node. The measured RSSI values are used in LNSM to find distance [23, 24].

$$
P_{L}(d)=P_{t}(d B m)-P_{r}(d)(d B m)
$$

$\mathrm{P}_{\mathrm{L}}$ - Total path loss in $\mathrm{dB} ; \mathrm{P}_{\mathrm{t}}$ - Transmitted power in $\mathrm{dBm} ; \mathrm{P}_{\mathrm{r}}-$ Received power in $\mathrm{dBm}$. Propagation model used in wireless sensor network is given by

$$
P_{L}(d)=P_{L}\left(d_{0}\right)+10 n \log \left(d / d_{0}\right)+X_{\sigma}
$$

Where ' $P_{L}\left(d_{0}\right)$ ' is the path loss at the reference distance $d_{0}$ in $d B$, For this experiment ' $d_{0}$ ' is taken as $1 \mathrm{~m}$, ' $d$ ' is the distance from sender, ' $\mathrm{n}$ ' is the path loss exponent, ' $\mathrm{X}_{\sigma}$ ' is the zero-mean Gaussian random variable. Path loss exponent measures the rate at which the RSS decreases with distance, and its value depends on the specific propagation environment

$$
P_{r}(d)=A-10 n \log (d)
$$

Where $\mathrm{A}=\mathrm{P}_{\mathrm{t}}-\mathrm{P}_{\mathrm{L}}\left(\mathrm{d}_{0}\right)$ is the received signal at $1 \mathrm{~m}$ distance. Linear regression analysis is used to compute 'A' and $\sigma$ value based on the measured data. The RSSI values are collected at the target node which is at known distances away from the Beacon nodes. Crammer's rule can be used to find the values of A and $\mathrm{n}$.

$$
\begin{aligned}
& \mathrm{T}=\left(\mathrm{M}^{\mathrm{T}} \mathrm{M}\right)^{-1} \mathrm{M}^{\mathrm{T}} \mathrm{R} \\
& \mathrm{T}=\left[\begin{array}{l}
\mathrm{A} \\
\mathrm{n}
\end{array}\right], \mathrm{M}=\left[\begin{array}{ll}
1 & 10 \log \mathrm{d}_{1} \\
1 & 10 \operatorname{logd} \mathrm{d}_{2} \\
1 & 10 \operatorname{logd} \mathrm{d}_{3} \\
1 & 10 \operatorname{logd} \mathrm{d}_{4}
\end{array}\right], \mathrm{R}=\left[\begin{array}{l}
\mathrm{RSSI}_{1} \\
\mathrm{RSSI}_{2} \\
\mathrm{RSSI}_{3} \\
\mathrm{RSSI}_{4}
\end{array}\right]
\end{aligned}
$$

Where $d_{1}, d_{2}, d_{3}, d_{4}$ represent the distances between the target and the respective beacon nodes and RSSI $\mathrm{RSSI}_{2}, \mathrm{RSSI}_{3}, \mathrm{RSSI}_{4}$ are the RSSI mean values collected from the beacon nodes. The below equation is used to calculate distance from RSSI measurements.

$$
\mathrm{d}=10^{\frac{\left(\mathrm{A}-\mathrm{Pr}_{\mathrm{r}}\right)}{10 \mathrm{n}}}
$$

The above equation is used to calculate distance from RSSI measurements. Where ' $n$ '-Path loss exponent; $\mathrm{P}_{\mathrm{r}}-$ Received power in $\mathrm{dBm}$; Multilateration is implemented to find the position of a unknown node. Four beacon nodes positions are kept at reference to find the unknown node's position. The multilateration method has been selected due to its good computational cost-accuracy trade-off [25]. If the beacon nodes are located at $\left(\mathrm{x}_{1}, \mathrm{y}_{1}\right),\left(\mathrm{x}_{2}, \mathrm{y}_{2}\right),\left(\mathrm{x}_{3}, \mathrm{y}_{3}\right),\left(\mathrm{x}_{4}, \mathrm{y}_{4}\right)$ then the position of the target $(\mathrm{x}$, y) can be obtained using (6) as

$$
\begin{aligned}
& d_{1}^{2}=\left(x-x_{1}\right)^{2}+\left(y-y_{1}\right)^{2} \\
& d_{2}^{2}=\left(x-x_{2}\right)^{2}+\left(y-y_{2}\right)^{2} \\
& d_{n}^{2}=\left(x-x_{n}\right)^{2}+\left(y-y_{n}\right)^{2}
\end{aligned}
$$




\section{KALMAN FILTER}

The objective of the Kalman filter is to minimize the mean square error between the actual and estimated data. It estimates the states of a process in two steps, predictor state and corrector state [26, 27]. Predictor state: This state calculates an estimate of the future state of the system from the previous state estimate.

Update expected value of $\mathrm{X} \mathrm{X}_{\mathrm{k}}=\mathrm{AX} \mathrm{k}-1+\mathrm{BU}$

Update error covariance matrix

$$
\mathrm{P}_{\mathrm{k}}=\mathrm{AP}_{\mathrm{k}-1} \mathrm{~A}^{\mathrm{T}}+\mathrm{Q}
$$

Where, $\mathrm{X}_{\mathrm{k}}$ is state estimate at step $\mathrm{k}=\left[\begin{array}{c}\text { positionX } \\ \text { positionY } \\ \text { velocityX } \\ \text { velocityY }\end{array}\right]$

A $(\mathrm{n} \times \mathrm{n})$ matrix that relates the step of $\mathrm{k}-1$ to current state $\mathrm{k}$

A is taken as $\left[\begin{array}{cccc}1 & 0 & \Delta \mathrm{t} & 0 \\ 0 & 1 & 0 & \Delta \mathrm{t} \\ 0 & 0 & 1 & 0 \\ 0 & 0 & 0 & 1\end{array}\right], \Delta \mathrm{t}$ represents the sampling period, $\mathrm{B}(\mathrm{n} \times 1)$ matrix that relates $\mathrm{U}$ to the state $\mathrm{X}, \mathrm{B}$ is taken as $\left[\begin{array}{c}\Delta \mathrm{t}^{2} / 2 \\ \Delta \mathrm{t}^{2} / 2 \\ \Delta \mathrm{t} \\ \Delta \mathrm{t}\end{array}\right]$, Where ' $\mathrm{U}$ ' is the optional control input; ' $\mathrm{P}_{\mathrm{k}}$ ' is the error covariance; ' $\mathrm{Q}$ ' is the process noise covariance.

Corrector (Measurement update) state: First step loin this state is calculation of Kalman gain. The second step is to update expected value and the final step is updation of error covariance matrix.

$$
\begin{aligned}
& \text { Compute Kalman gain } \mathrm{K}_{\mathrm{k}}=\mathrm{P}_{\mathrm{k}-1} \mathrm{H}^{\mathrm{T}}\left(\mathrm{HP}_{\mathrm{k}-1} \mathrm{H}^{\mathrm{T}}+\mathrm{R}\right)^{-1} \\
& \text { Update expected value } \mathrm{X}_{\mathrm{k}}=\mathrm{X}_{\mathrm{k}-1}+\mathrm{K}_{\mathrm{k}}\left(\mathrm{Z}_{\mathrm{k}}-\mathrm{HX} \mathrm{X}_{\mathrm{k}-1}\right) \\
& \text { Update error covariance } \mathrm{P}_{\mathrm{k}}=\left(1-\mathrm{K}_{\mathrm{k}} \mathrm{H}\right) \mathrm{P}_{\mathrm{k}-1}
\end{aligned}
$$

$\mathrm{H}(\mathrm{m} \times \mathrm{n})$ matrix that relates the state $\mathrm{X}_{\mathrm{k}}$ to the measurement $\mathrm{Z}_{\mathrm{k}}$ by $\mathrm{Z}_{\mathrm{k}}=\mathrm{HX} \mathrm{X}_{\mathrm{k}}+\mathrm{G}$

Measurement noise covariance is represented by random variable ' $G$ '. $Q$ and $G$ are assumed to be independent (of each other), and with normal probability distributions. In practice, the process noise covariance and measurement noise covariance matrices might change with each time step or measurement, however here we assume they are constant. The time update projects the current state estimate ahead in time. The measurement update adjusts the projected estimate by an actual measurement at that time. The filter works in a recursive manner. After each time and measurement update, the steps are repeated with the previous posterior estimates used to project or predict the new a priori estimates. The Kalman filter recursively generate a current estimate based on all of the past measurements.

\section{MOTE TRACK IN-OUT SYSTEM}

Flow diagram of target tracking using MoteTrack InOut system is shown in Figure 2. TelosB motes are used to measure real time RSSI values in an outdoor environment. After distance and position estimation using these measurements, position error is calculated. In order to reduce position error a new algorithm is developed. Kalman filter is applied after this algorithm to track the target and to reduce the measurement error. The MoteTrack InOut system works upon the following algorithm.

1) Collect RSSI values from beacon nodes and calculate the average of RSSI measurements of each beacon node. Find path-loss exponent 'n'and 'A'.

2) Estimate distance from log normal shadowing model

3) Find distance error $\left(D_{E}\right)$.

$\mathrm{D}_{\mathrm{E}}=$ Actual distance $\left(\mathrm{d}_{\mathrm{A}}\right)-$ Calculated distance $\left(\mathrm{d}_{\mathrm{C}}\right)$

4) Find average distance error $\left(\mathrm{A}_{\mathrm{DE}}\right)$. 


$$
A_{D E}=\frac{\text { Actual distance }\left(d_{A}\right)-\text { Calculated distance }\left(d_{C}\right)}{\text { Total number of measurements taken }(N)}
$$

5) Average distance error $A_{D E}$ is negative value,

a. If the distance error $\left(D_{E}\right)$ is positive, $A_{D E}$ will be added to $D_{E}$. Then the Resultant error reduction $\left(R E_{R}\right)$ is

$\mathrm{RE}_{\mathrm{R}}=\mathrm{D}_{\mathrm{E}}+\left(-\mathrm{A}_{\mathrm{DE}}\right)$

b. If $D_{E}$ is negative, $A_{D E}$ will be subtracted from $D_{E}$. Then the $R E_{R}$ is

$R E_{R}=-D_{E}-\left(-A_{D E}\right)$.

6) $\mathrm{A}_{\mathrm{DE}}$ is positive value,

a. If $D_{E}$ is negative, $A_{D E}$ will be added to $D_{E}$. Then the $R E_{R}$ is

$R E_{R}=-D_{E}+A_{D E}$

b. If $D_{E}$ is positive, $A_{D E}$ will be subtracted from $D_{E}$.

$\mathrm{RE}_{\mathrm{R}}=\mathrm{D}_{\mathrm{E}}-\mathrm{A}_{\mathrm{DE}}$.

7) If $R E_{R}$ is greater than the $D_{E}$ value, then $D_{E}$ is considered as $R E_{R}$. Calculate average distance error reduction $\left(\mathrm{AE}_{\mathrm{R}}\right)$.

8) Calculate the percentage of error reduction from $A_{R}$ and $A_{D E}$.

9) Find node's position and position error $P_{E}$

$$
\mathrm{P}_{\mathrm{E}}=\frac{\sum_{\mathrm{k}=1}^{\mathrm{N}} \sqrt{\left(\mathrm{x}_{\mathrm{k}}-\mathrm{x}_{\mathrm{Cal}_{\mathrm{k}}}\right)^{2}+\left(\mathrm{y}_{\mathrm{k}}-\mathrm{y}_{\mathrm{cal}_{\mathrm{k}}}\right)^{2}}}{\mathrm{~N}}
$$

$\left(\mathrm{x}_{\mathrm{cal}_{\mathrm{k}}}, \mathrm{y}_{\mathrm{cal}_{\mathrm{k}}}\right)$ is the calculated position and $\left(\mathrm{x}_{\mathrm{k}}, \mathrm{y}_{\mathrm{k}}\right)$ is the actual position of the target at $\mathrm{k}^{\text {th }}$ position.

When position error $\left(\mathrm{P}_{\mathrm{E}}\right)$ is minimum better performance of the localization system is achieved.

10) Repeat steps from 1 to 9 for various beacon positions.

11) Implement Kalman Filter

a. Initialize the matrices $\mathrm{A}, \mathrm{B}, \mathrm{C}$ of the state equation

b. Set the initial velocity to zero and set the initial position

c. for $\mathrm{k}=1$ to $25 \mathrm{do}$

$$
\begin{aligned}
\text { i. } & \mathrm{X}_{\mathrm{k}}=\mathrm{AX}_{\mathrm{k}-1}+\mathrm{BU} \\
\text { ii. } & \mathrm{P}_{\mathrm{k}}=\mathrm{AP}_{\mathrm{k}-1} \mathrm{~A}^{\mathrm{T}}+\mathrm{Q} \\
\text { iii. } & \mathrm{K}_{\mathrm{k}}=\mathrm{P}_{\mathrm{k}-1} \mathrm{H}^{\mathrm{T}}\left(\mathrm{HP}_{\mathrm{k}-1} \mathrm{H}^{\mathrm{T}}+\mathrm{G}\right)^{-1} \\
\text { iv. } & \mathrm{X}_{\mathrm{k}}=\mathrm{X}_{\mathrm{k}-1}+\mathrm{K}_{\mathrm{k}}\left(\mathrm{Z}_{\mathrm{k}}-\mathrm{HX}_{\mathrm{k}}\right) \\
\text { v. } & \mathrm{P}_{\mathrm{k}}=\left(1-\mathrm{K}_{\mathrm{k}} \mathrm{H}\right) \mathrm{P}_{\mathrm{k}-1}
\end{aligned}
$$

d. end for

12) Plot the localization graph.

This algorithm is used to reduce the position error in indoor and outdoor environments.

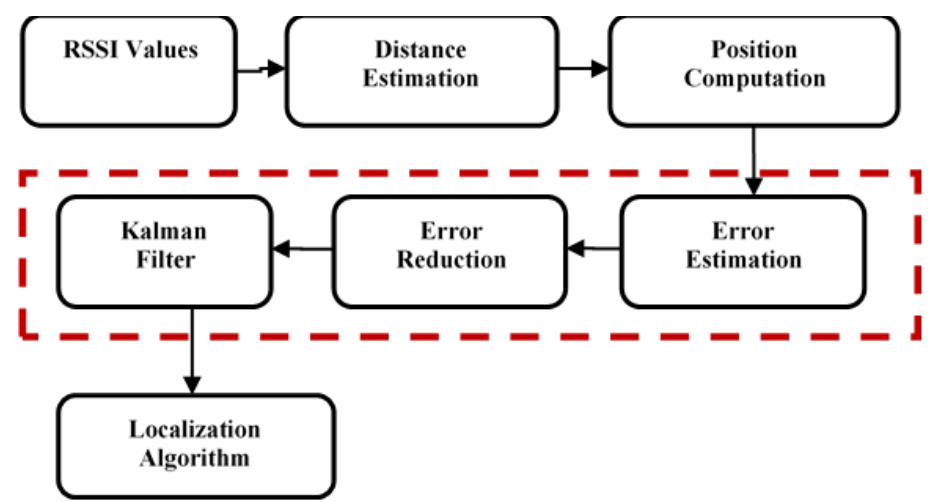

Figure 2. Flow diagram of motetrack inout system

\section{TARGET TRACKING COMPARED WITH OTHER METHODS}

Kalman filter is widely used in control systems to estimate the state of a process in presence of noisy measurements. It estimates the states of a process by minimizing mean square error between the ideal and real system states. 


\subsection{Outdoor Environment System Model}

Table 1 shows the parameters involved for the RSSI measurements in an outdoor environment. Four anchor nodes are used for this experiment and it is named as $\mathrm{N}_{1}, \mathrm{~N}_{2}, \mathrm{~N}_{3}$ and $\mathrm{N}_{4}$. Readings are taken in 128 different positions using non-anchor node. From Figure 3 to Figure 6 show the final simulation results of the localization system. The result compares the actual path with the estimated path. Right subplot of Figure 3 represents the actual path followed by the moving target. Every measurement was carried out on the marked points (blue colour square boxes). Anchor node positions are shown in red colour small circle. Left subplot of Figure 3 shows the tracking without applying the filter. Here the tracking is done only using log-normal shadowing model (LNSM). The average position error per position is $3.425 \mathrm{~m}$. As shown in Figure 3, the obtained path doesn't draw the actual path. Some of the results go beyond the boundaries.

Figure 4 compares the actual path with the one obtained after Kalman filter is implemented. Left subplot of Figure 4 shows the path obtained after filtering the positions. The Kalman Filter smoothen the path as well as reduces the error. The error in the estimation of the target is reduced to $2.112 \mathrm{~m}$.n Figure 5 compares the actual path with the one obtained after proposed method before applying Kalman filter is implemented. Left subplot of Figure 5 shows the path obtained after filtering the positions. The proposed method reduces the error as well as smoothen the path but in some places overlapping occurred. The error in the estimation of the target is reduced to $1.251 \mathrm{~m}$.

Table 1. Real time outdoor parameters

\begin{tabular}{|c|c|c|c|c|c|c|}
\hline $\begin{array}{l}\text { Number of Anchor } \\
\text { nodes used }\end{array}$ & $\begin{array}{c}\text { Anchor node } \\
\text { positions }\left(\mathrm{N}_{1}, \mathrm{~N}_{2}, \mathrm{~N}_{3}, \mathrm{~N}_{4}\right)\end{array}$ & $\begin{array}{l}\text { Number of mobile } \\
\text { nodes used }\end{array}$ & Mote & $\begin{array}{c}\text { Number of } \\
\text { positions used }\end{array}$ & $\begin{array}{l}\text { Operating } \\
\text { System }\end{array}$ & Simulation \\
\hline 4 & $(0,1),(0,2.5),(1,7.1),(2.5,7.1)$ & 6 & TelosB & 128 & TinyOS & MATLAB \\
\hline
\end{tabular}
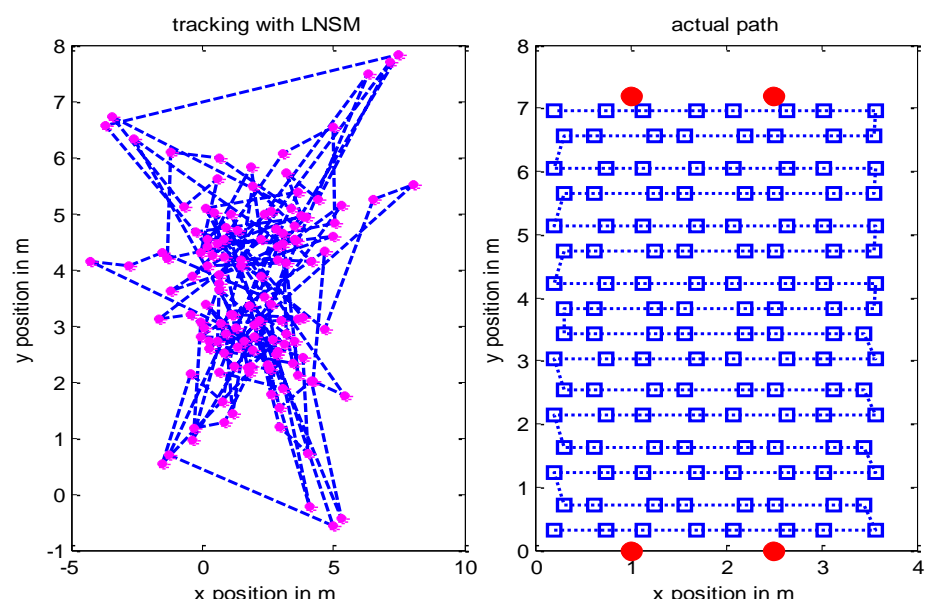

Figure 3. Plot comparing the actual path with estimated path obtained using LNSM
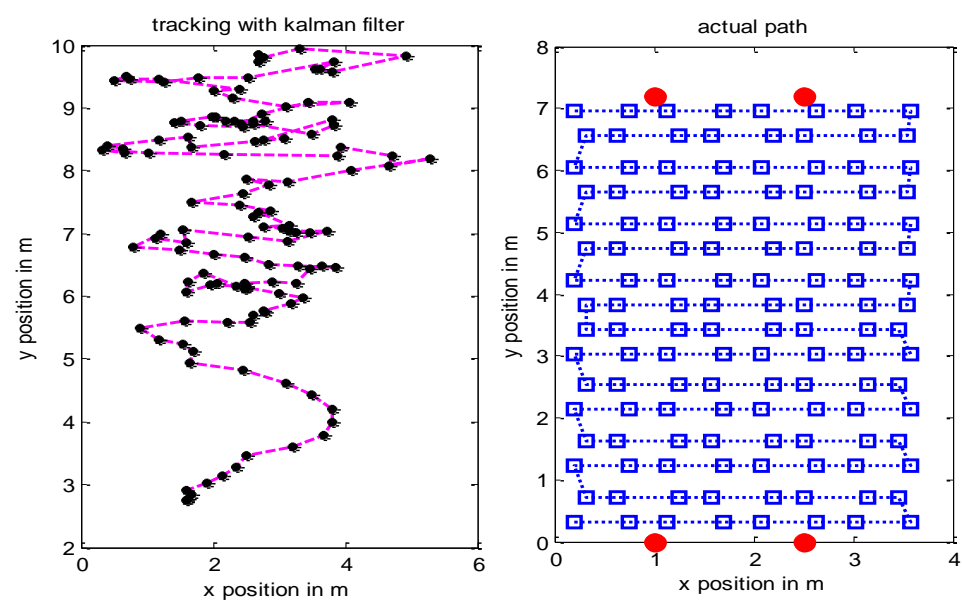

Figure 4. Plot comparing the actual path with estimated path using kalman filter 

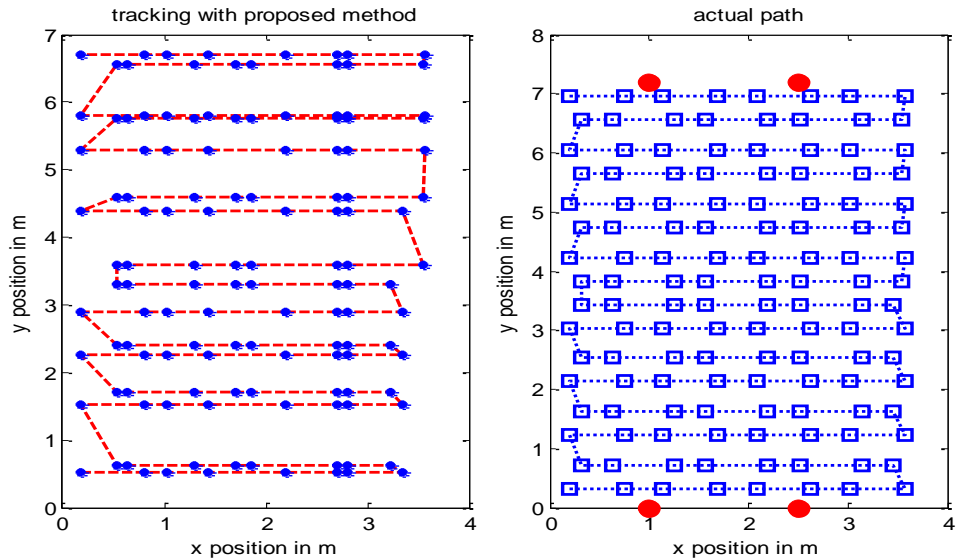

Figure 5. Plot comparing the actual path with estimated path obtained using proposed method before applying kalman filter

Figure 6 compares the actual path with the one obtained after MoteTrack InOut is implemented. It is found that localization error is $0.834 \mathrm{~m}$ and there is no overlapping in the tracking path. The Localization errors obtained using the proposed method and various other methods are shown in the Table 2.
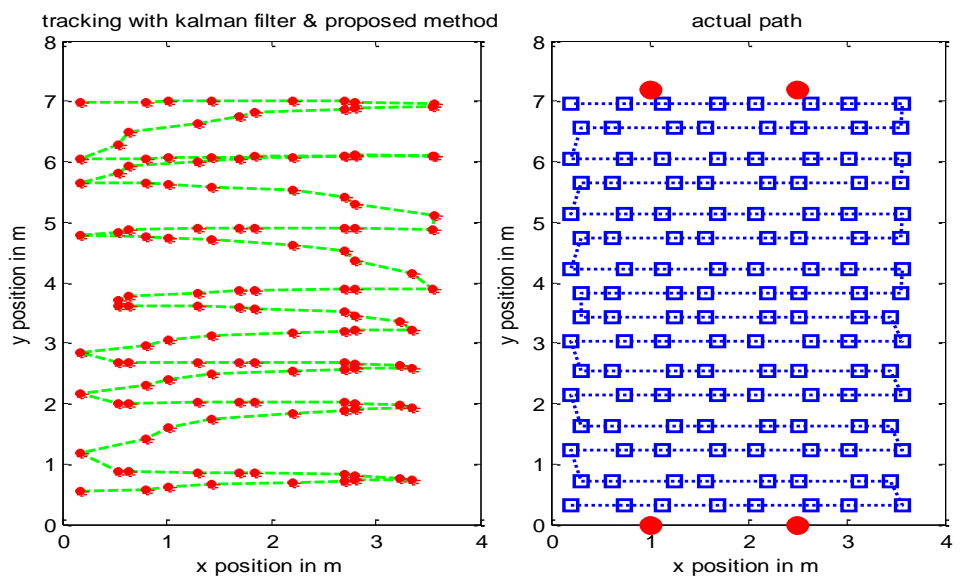

Figure 6. Plot comparing the actual path with estimated path obtained using motetrack inout system

Table 2. Localization error calculated for the real time RSSI values under different methods

\begin{tabular}{ll}
\hline Method & Localization Error $((\mathrm{m})$ \\
\hline LNSM & 3.425 \\
Kalman filter & 2.112 \\
Proposed method without Kalman filter & 1.251 \\
MoteTrack InOut System & 0.834 \\
\hline
\end{tabular}

\section{CONCLUSION}

In an outdoor environment, for a moving target the localization error using LNSM, Kalman filter and proposed method before implementing Kalman filter is $3.425 \mathrm{~m}, 2.112 \mathrm{~m}$ and $1.251 \mathrm{~m}$ respectively. The localization error is reduced using proposed method but over lapping occurred in the tracking path. Proposed algorithm with the Kalman Filter is used and it is found that localization error is $0.834 \mathrm{~m}$ and there is no overlapping in tracking path. Localization error reduction obtained using the MoteTrack InOut system for a moving target is $2.51 \mathrm{~m}$ when compared to LNSM. Localization error reduction of $74.5 \%$ and $75.6 \%$ are obtained for indoor and outdoor respectively using Motetrack InOut system for a moving target compared to LNSM. 


\section{REFERENCES}

[1] Akyildiz, W. Su, Y. Sankarasubramaniam, and E. Cayirci, "Wireless sensor networks: A survey," Computer Networks Journal, vol. 38(4), pp. 393-422, 2002.

[2] D. Estrin, L. Girod, G. Pottie and M. Srivastava, "Instrumenting the world with wireless sensor networks," International Conference on Acoustics, Speech, and Signal Processing (ICASSP 2001), pp. 2685-2678, 2001.

[3] C. Otto, A. Milenkovic, C. Sanders and E. Jovanov, "System architecture of a wireless body area sensor network for ubiquitous health monitoring," Journal of Mobile Multimedia, vol. 1(4), pp. 307-326, 2006.

[4] Alaa jabber, Robert Bicker, "Design of a Wireless Sensor Node for Vibration Monitoring of Industrial Machinery", International Journal of Electrical and Computer Engineering (IJECE), Vol. 6((5), pp. 639-653, April 2016

[5] Fatma Karray, Mariem Triki, Mohamed Wassim Jmal , Mohamed Abid, and Abdulfattah M. "WiRoTip: an IoTbased Wireless Sensor Network for Water Pipeline Monitoring," International Journal of Electrical and Computer Engineering (IJECE), Vol. 8, No. 5, pp. 3250 - 3258, October 2018.

[6] Huang, X. "Target Localization Based on Improved DV-Hop Algorithm in Wireless Sensor Networks," Journal of Networks, vol 38(4), pp.393-422, 2014.

[7] Nguyen, T. L. N., Shin, Y. "Multiple Target Larget Localization in WSNs based on Compressive Sensing Using Deterministic Sensing Matrices,” International Journal of Distributed Sensor Networks, 16, pp.1-8, 2015.

[8] Pal, A, "Localization Algorithms in Wireless Sensor Networks:Current Approaches and Future Challenges. Network Protocols and Algorithms," Network Protocols and Algorithms, 2(1), pp. 45-73, 2010.

[9] Yao, Y. "A RSSI-Based Distributed Weighted Search Localization Algorithm for WSNs," International Journal of Distributed Sensor Networks, 29(3), pp.1-11, 2015.

[10] Cui, F. "Weighted Centroid Localization Algorithm based on Multilateral Localization Error of Received Signal Strength Indicator," Infrared and Laser Engineering, 44(7), pp. 2162-2168, 2015.

[11] Mahdy Nabaee, Ali Olfat, "Enhanced RSS based location estimation with disk overlapping in wireless sensor networks," IEEE International Conference on Telecommunications, 2008.

[12] Chin-Liang Wang, Yih-Shih Chiou, Yu-Sheng Dai, "An adaptive location estimator based on kalman filtering for wireless sensor networks," IEEE 65th International Conference on Vehicular Technology, 2007.

[13] Chin-Liang Wang, Yih-Shih Chiou, "An adaptive positioning scheme based on radio propagation modeling for indoor WLANs," IEEE 63rd International Conference on Vehicular Technology, 2006.

[14] Jamin Lee, Hyungjoon Song, Sungmok Oh, Daesik Hong, "An improved location tracking algorithm with velocity estimation in cellular radio networks," IEEE 63rd International Conference on Vehicular Technology, 2006.

[15] Po-Hsuan Tseng, Chao-Lin Chen, Kai-Ten Feng, "A unified kalman tracking technique for wireless location systems," 2nd International Symposium on Wireless Pervasive Computing (ISWPC '07), 2007.

[16] S. Umesh Babu, C. S. Kumar, R. V. Raja kumar, "Sensor networks for tracking a moving object using kalman filtering," IEEE International Conference on Industrial Technology (ICIT), 2006.

[17] Giovanni Zanca, Francesco Zorzi, Andrea Zanella and Michele Zorzi, "Experimental comparison of RSSI-based localization algorithms for indoor wireless sensor networks," Proceedings of the workshop on Real-world wireless sensor networks, pp. 1-5, 2018.

[18] José Ramiro Martínez-de Dios, Anibal Ollero, Francisco José Fernández and Carolina Regoli, "On-line RSSI-range model learning for target localization and tracking," Journal of Sensor and Actuator Networks, vol. 6(15), pp. 1-19, 2017.

[19] Sadik Kamel Gharghan, Rosdiadee Nordin, Aqeel Mahmood Jawad, Haider Mahmood Jawad, and Mahamod Ismail, "Adaptive neural fuzzy inference system for accurate localization of wireless sensor network in outdoor and indoor cycling applications," IEEE Access, vol. 6, pp. 38474-38489, 2018.

[20] K. Vadivukkarasi, R. Kumar, Mary Joe, "Real time RSSI based novel algorithm to improve indoor localization accuracy for target tracking in wireless sensor networks," ARPN journal of engineering and applied sciences, vol. 10(16), pp. 7015-7023, 2015.

[21] TelosB mote platform datasheet, http://www.willow.co.uk/TelosB_Datasheet.pdf.

[22] "CC2420 Radio Data Sheet Revision 1.3." http://www.chipcon.com/files/CC2420 Data Sheet 13.pdf, October 2005.

[23] T. S. Rappaport, "Wireless communications: principles and practice", 2nd edition, Prentice Hall, 2002.

[24] Chuan-Chin $\mathrm{Pu}$, and Wan-Young Chung, "Mitigation of multipath fading effects to improve indoor RSSI performance," IEEE Sensors Journal, vol. 8(11), pp 1884-1886, 2008.

[25] Jokhio S. H., Jokhio I. A., Kemp A. H., "Light-weight framework for security-sensitive wireless sensor networks applications," Wireless Sensor Systems, IET, vol. 3(4), pp. 298-306, 2013.

[26] Abdalkarim A wad, Thorsten Frunzkeand Falko Dresslerr, "Adaptive distance estimation and localization in SN using RSSI measures," IEEE 10th Euromicro Conference on Digital System Design Architectures, Methods and Tools, pp. 471-478, 2007.

[27] Pashazadeh S, Sharifi M., "A geometric modelling approach to determining the best sensing coverage for 3-dimensional acoustic target tracking in wireless sensor networks," Sensors journal, vol. 9(9), pp. 6764-6794, 2009. 


\section{BIOGRAPHIES OF AUTHORS}
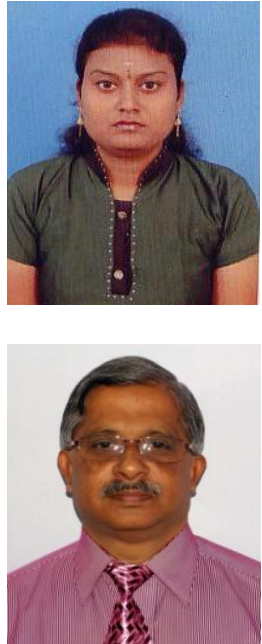

K. Vadivukkarasi received her PhD degree from SRM University, India (2016), Master of Engineering degree in Embedded System Technology from Anna University, Tamilnadu, India in 2007 and Bachelor of Engineering degree in Electronics and Communication Engineering from Madras University, Tamilnadu, India, in 2001. She is working an assistant professor in the Department of Electronics and Communication Engineering, SRM University, India. Her main research interests are in wireless sensor networks, Embedded system design, Embedded networking and Internet of Things.

R. Kumar received his PhD degree from SRM University, India (2009), Master of science from BITS Pilani (1993) and bachelor's degree in Electronics and Communication Engineering from Bharathidasan University, 1989. He is working as a professor in the Department of Electronics and Communication Engineering, SRM University, Chennai, India. His areas of interest include spread spectrum techniques, wireless communication, wireless sensor networks MIMO-OFDM systems and under water fiber optic communication. He has supervised a number of undergraduate, postgraduate as well as $\mathrm{PhD}$ students in the area of wireless communication. His research work led him to publish more than 100 papers in journals and in conferences. 